\title{
Influence of grain size on radiation effects in a low carbon steel
}

\author{
Ahmad Alsabbagh $^{\mathrm{a}, *}$, Ruslan Z. Valiev ${ }^{\mathrm{b}}$, K.L. Murty ${ }^{\mathrm{a}}$ \\ ${ }^{a}$ Department of Nuclear Engineering, North Carolina State University, USA \\ ${ }^{\mathrm{b}}$ Institute of Physics of Advanced Materials, Ufa State Aviation Technical University, Russia
}

\section{A R T I C L E I N F O}

\section{Article history:}

Received 11 April 2013

Accepted 22 July 2013

Available online 29 July 2013

\begin{abstract}
A B S T R A C T
Ultra-fine grain (UFG) metals with a relatively large volume of interfaces are expected to be more radiation resistant than conventional metals; grain boundaries act as unsaturable sinks for neutron irradiation induced defects. Effects of neutron irradiation on conventional and ultra-fine grain structured carbon steel are studied using the PULSTAR reactor at NC State University to relatively low fluence $\left(\sim 1.15 \times 10^{-3} \mathrm{dpa}\right)$. The low dose irradiation of ultrafine grained carbon steel revealed minute radiation effects in contrast to the observed radiation hardening and reduction of ductility in its conventional grained counterpart.
\end{abstract}

Published by Elsevier B.V.

\section{Introduction}

As the demand for energy and the interest for reduction of carbon dioxide emissions increases in the world, renewed interest in nuclear energy emerged. In 2000, the US Department of Energy launched the Generation-IV Initiative to expand nuclear energy and provide improved safety, economy and sustainability of the nuclear power plant systems. Gen IV reactors will have higher temperatures and irradiation levels, and will use different coolants than current generation reactors [1,2]. The severe radiation environments of the advanced reactors require materials that can withstand these conditions and are suitable for such applications. To design enhanced radiation-tolerant materials, it's important to understand the way the radiation induced defects alter the material properties.

Nanocrystalline (NC) and ultra-fine grain (UFG) metals with a relatively large volume of interfaces are expected to be more radiation resistant than conventional metals $[3,4]$. Point and line defects produced by neutron radiation exposure migrate to the interfaces wherein they get absorbed thereby not being available for radiation hardening and embrittlement. It has been demonstrated that the defect density reduces drastically for metals with nano size grains below around $50 \mathrm{~nm}$ [5-7]. The large volume fraction of grain boundaries in ultra-fine structured metals can be a significant sink for radiation induced defects. Hence, the ultra-fine structured materials can play a significant role in designing radiation resistance materials [7]. The numerous interfaces of the nano and UF materials provide high density of short diffusion paths which enhance the self-diffusivity. Moreover, it was reported that

\footnotetext{
* Corresponding author. Tel.: +19198026351; fax: +19195155115.

E-mail address: ahalsabb@ncsu.edu (A. Alsabbagh).
}

the solute solubility increased in nano-structural materials compared to its coarse grain counterpart [8].

The experimental data on the radiation effect on ultra-fine structured materials is very limited and most of the past studies were conducted using ion irradiation which would not have the same effect as neutron irradiation because for the same incident particle energy, the heavier particles are slower, stopped easier and deposit their entire energy over much shorter distances. Thus, a number of fine grain structured carbon steel samples were irradiated in the PULSTAR reactor at North Carolina State University (NCSU) along with their conventional counterparts to characterize the effect of neutron irradiation on low carbon steel of ultrafine grain size and compare the results with those of the conventional grain (grains larger than one micrometer) steel to assess whether this large grain surface area per unit volume prevents, delays or minimizes the effects of radiation damage.

While nano grained materials have a grain size less than $100 \mathrm{~nm}$, ultra-fine grained materials are with grain size between $100 \mathrm{~nm}$ and $1000 \mathrm{~nm}$ [9]. UFG and NC materials can be produced by two major approaches [10]: bottom-up methods which involve consolidating nano or ultra-fine grained materials from the atomic scale; examples of methods that use this approach are electrodeposition [11] and inert gas condensation [12,13]. The second method is the top-down approach that involves refining the coarse grain materials to produce the UFG and NC ones. Severe plastic deformation (SPD) is the common technique for this approach; it imposes very high plastic strain in the material to refine its grain size [14]. Two basic procedures for SPD are used to produce the ultra-fine grained materials: high pressure torsion (HPT) [15] and equal channel angular pressing (ECAP) procedure $[16,17]$. While HPT produces relatively small size specimens, ECAP technique provides large bulk metals and considered as one of the most efficient techniques in producing ultra-fine grained materials by SPD [17]. 
In ECAP, the material will be pressed in an angular die to introduce high strain. Hence, the material will experience shear deformation without changing its cross-sectional dimensions. Fig. 1a shows a schematic illustration of ECAP processing where the $X$ plane (perpendicular to the pressing direction), and $Y, Z$ planes (side and top faces of the pressed sample) have the same dimensions as of the original specimen. The combination of high pressure and huge uniform shear strain that is applied on the material will result in a considerable refining of the grains. Thus, larger grain boundary surface area per unit volume will be produced. Since the grains are oriented in different directions, dislocations will need more energy to travel to the adjacent grains and this impediment of dislocation movement will prevent the plastic behavior of the material, leading to improvement in the strength.

Since the cross-sectional dimensions remain the same through the ECAP technique, multiple passing of the processed sample through the die will increase the strain intensity and produce samples that are heavily deformed with uniform structure. The sample is inserted in the die and then it is removed, rotated and reinserted again in the die. Four processing routes have been identified to define the rotational angle between each passage through the die $(A$, $\mathrm{Ba}, \mathrm{BC}$ and C) [16-18]. Fig. 1b illustrates the difference between the ECAP processing routes; in route $A$ the sample is inserted in the die for the second pass without any rotation. For route Ba the sample is rotated $90^{\circ}$ in alternate direction. In route $\mathrm{Bc}$ the sample is rotated $90^{\circ}$ in the same direction after each pass while in route $C$ the sample is rotated through $180^{\circ}$ between each pressing. It was found that route $\mathrm{Bc}$ is the most efficient processing route [19] because of the eventual restoration of the cubic element after $4 n$ passes, where $\mathrm{n}$ is an integer. Many factors made the ECAP one of the unique industrial processes [20] such as the enormous deformation without changing the cross-sectional dimensions, the large size production of bulk metals, the uniform structure of the worked material and the low pressure that is needed for the extrusion in the ECAP.

\section{Material}

The ultra-fine grain low carbon steel used in this study has a w\% composition of $0.1 \% \mathrm{C}, 0.27 \% \mathrm{Si}, 0.5 \% \mathrm{Mn}$ and $99.13 \% \mathrm{Fe}$ and was processed through an ECAP die having channels intersecting at $90^{\circ}$ and using 4 passes ( $\mathrm{Bc}$ route). The strain introduced to the steel samples due to the ECA pressing was calculated using Iwahashi model [21] and it was found to be equal to 4.618. The inner contact angle $(\Phi)$ and the arc of curvature $(\Psi)$ at the outer point of contact between channels of the die were $90^{\circ}$ and $0^{\circ}$, respectively. The course grain counterparts were produced by annealing the UFG samples to $800^{\circ} \mathrm{C}$ for $1 \mathrm{~h}$. Micro-hardness measurements were performed using Buehler Micromet 5103 Instruments. Indentations were performed with a Vickers indenter tip using $0.5 \mathrm{~kg}$ load and for $10 \mathrm{~s}$ holding time. Ten indents were taken on each specimen to obtain good statistics. The micro-hardness values of the UFG steel samples before and after annealing process are shown in Fig. 2 and we note that the Vickers micro-hardness of the as-prepared and the post-annealed samples treated up to $420^{\circ} \mathrm{C}$ have nearly the same value equal to $3.09 \mathrm{GPa}$. Annealing at higher temperatures leads to a gradual decrease in the micro-hardness values of the samples to attain $1.28 \mathrm{GPa}$ for the sample that was annealed at $800{ }^{\circ} \mathrm{C}$ and this annealed material is considered as conventional grain micrometer sized (CG) steel in this study. X-ray diffraction was performed using a Rigku SmartLab X-ray diffractometer, the radiation source was $\mathrm{Cu} K \alpha 1(\lambda=0.154056 \mathrm{~nm})$ and the scan range was $40-120^{\circ}$.

The grain sizes for the pre-irradiated UFG and CG were investigated using electron backscattered diffraction (EBSD) and transmission electron microscopy (TEM); duplicate tests were made to obtain mean values of the grain size. The EBSD measurements were conducted on a Quanta 3D FEG scanning electron microscope. Crystallographic orientation mappings for UFG steel were taken using a step size of $70 \mathrm{~nm}$ in an area of $15 \mu \mathrm{m} \times 15 \mu \mathrm{m}$ while for the CG steel (Fig. 3b) a step size of $0.5 \mu \mathrm{m}$ in an area of

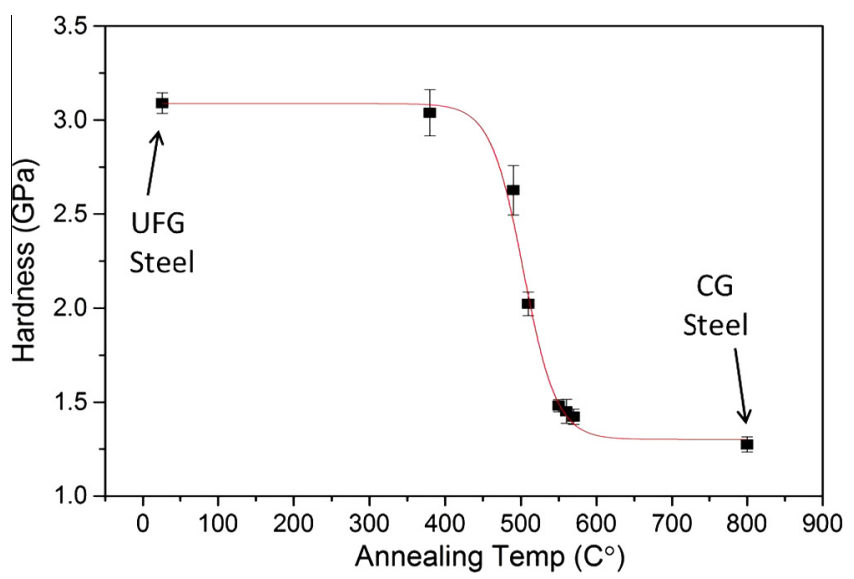

Fig. 2. Vickers micro-hardness values as a function of one hour annealing temperature.

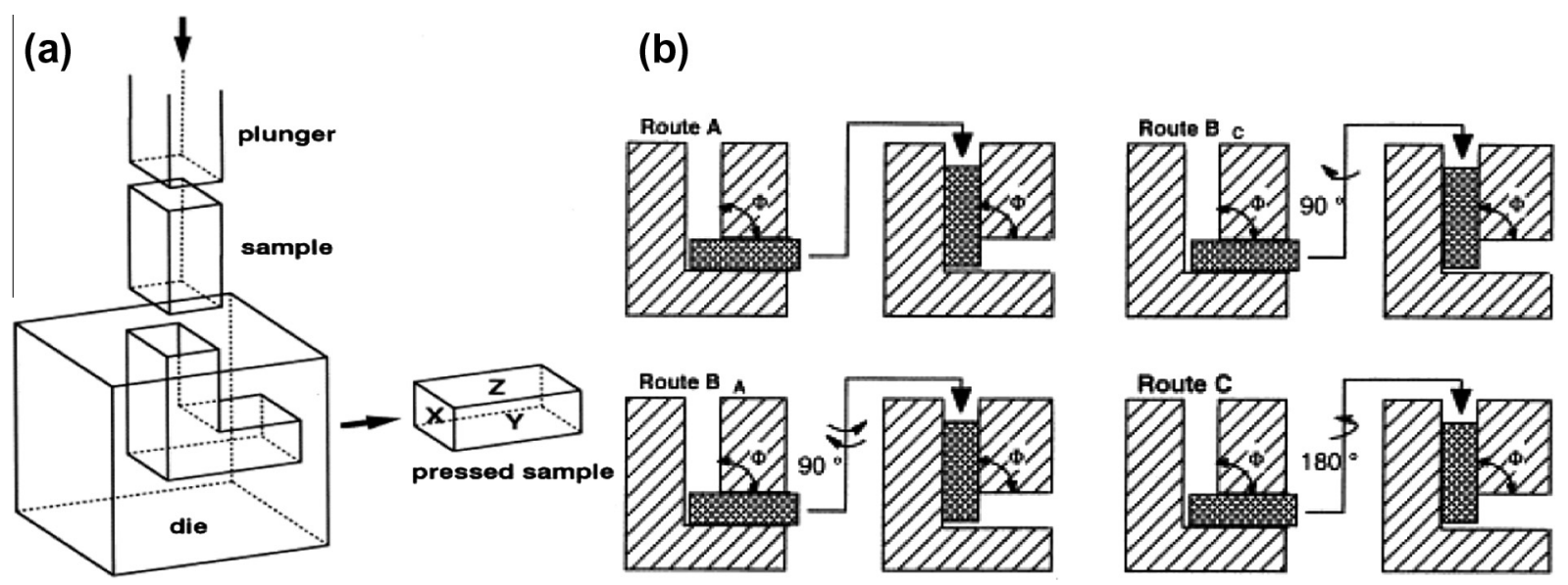

Fig. 1. Schematic illustration of a typical ECAP facility (a) and the rotational scheme of the four processing routes in ECAP (b) [16,17]. 

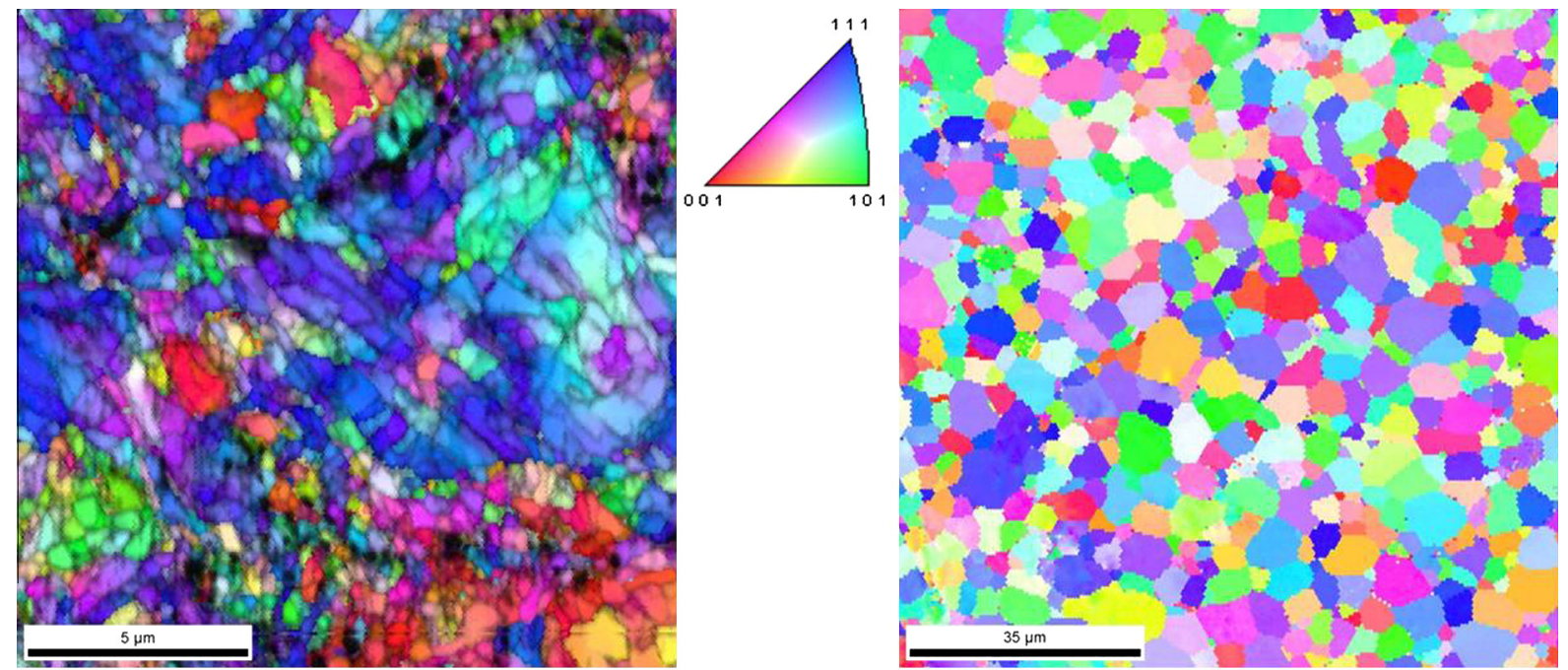

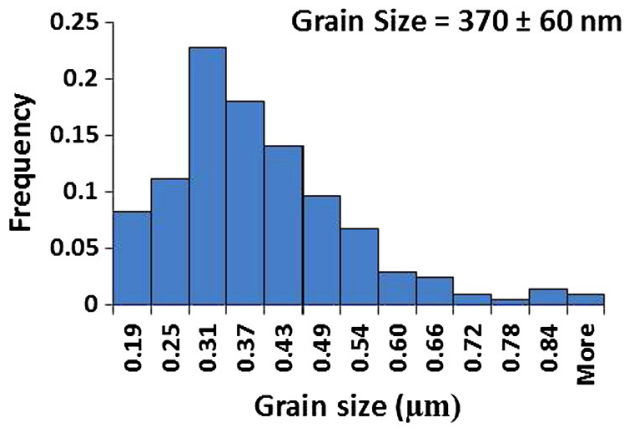

(a)

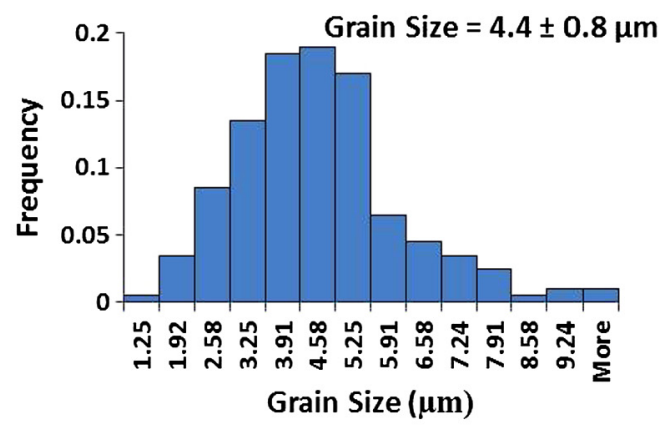

(b)

Fig. 3. Pre-irradiation EBSD patterns and grain size distributions for UFG (a) and CG steel (b).

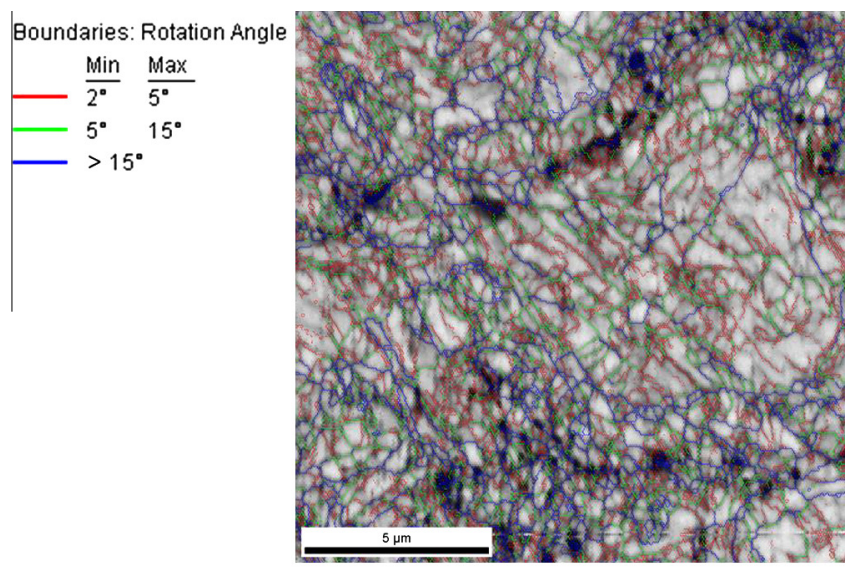

(a)

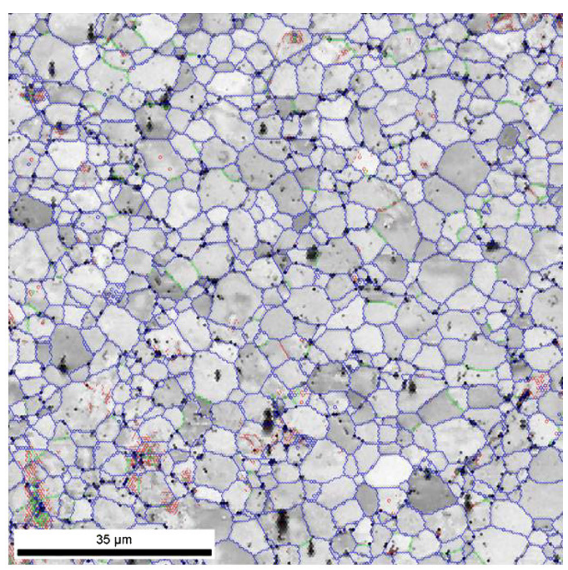

(b)

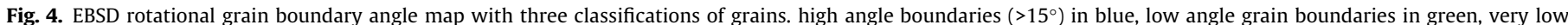

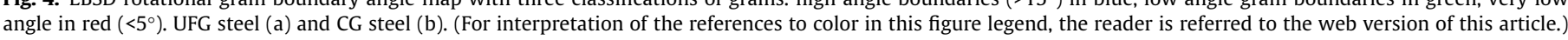

$100 \mu \mathrm{m} \times 100 \mu \mathrm{m}$ was used. The mean grain size for the UFG steel (Fig. 3) is about $370 \mathrm{~nm}$ (which agrees with the TEM results shown later) while it is about 12 times bigger for the CG steel with an average grain size of $4.4 \mu \mathrm{m}$. The colors in the image represent the different orientations, e.g., red, green and blue indicate the
(001), (101) and (111) planes respectively. From the grain boundary rotational angle map shown in Fig. 4 for both UF and CG steels, it's clear that the fraction of the small angle grain boundary (SAGB) is higher in the UFG steel than in CG; recrystallization and growth of the sub grains during annealing results in increasing the fraction 


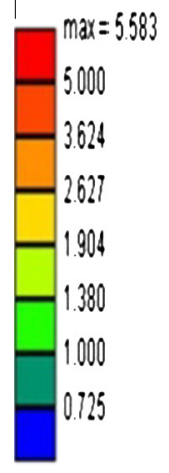

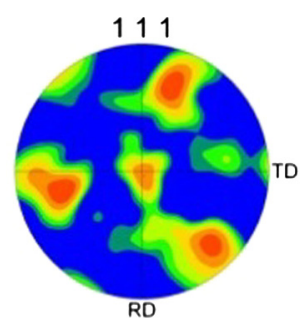

101
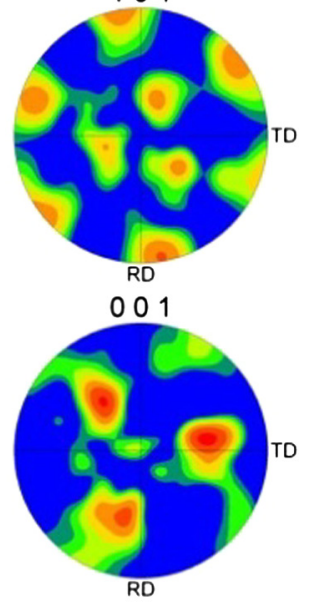

(a)

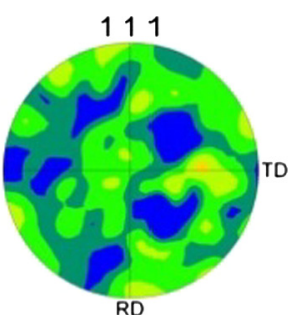

101

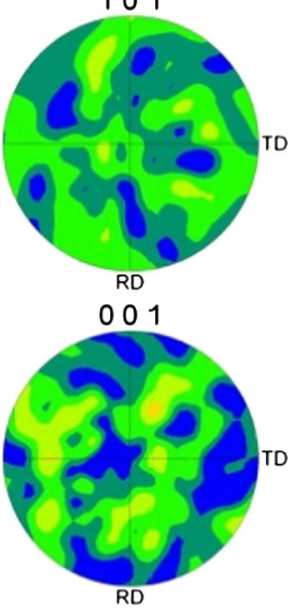

(b)

Fig. 5. EBSD pole figures for UFG steel (a) and CG steel (b) before irradiation.

Table 1

Characteristics of threshold reactions [24-26].

\begin{tabular}{|c|c|c|c|c|c|}
\hline Material & $\begin{array}{l}\text { Reactions } \\
\text { of interest }\end{array}$ & $\begin{array}{l}\text { Threshold } \\
\text { Energy } \\
(\mathrm{MeV})\end{array}$ & $\begin{array}{l}\text { Radio- } \\
\text { isotope } \\
\text { half life }\end{array}$ & $\begin{array}{l}\text { Gamma } \\
\text { ray } \\
\text { energy } \\
(\mathrm{KeV})\end{array}$ & $\begin{array}{l}\text { Gamma ray } \\
\text { abundance } \\
\text { (yield) (\%) }\end{array}$ \\
\hline \multirow[t]{2}{*}{$\mathrm{Ni}$} & $58 \mathrm{Ni}(\mathrm{n}, 2 \mathrm{n}) 57 \mathrm{Ni}$ & 13 & $35.6 \mathrm{~h}$ & 1377 & 81.70 \\
\hline & $58 \mathrm{Ni}(\mathrm{n}, \mathrm{p}) 58 \mathrm{Co}$ & 1 & 70.88 days & 810 & 99 \\
\hline \multirow[t]{2}{*}{$\mathrm{Al}$} & $27 \mathrm{Al}(\mathrm{n}, \alpha) 24 \mathrm{Na}$ & 4.5 & $14.96 \mathrm{~h}$ & 1368 & 100 \\
\hline & $27 \mathrm{Al}(\mathrm{n}, \mathrm{p}) 27 \mathrm{Mg}$ & 2.25 & $9.46 \mathrm{~min}$ & 843 & 100 \\
\hline Mg & $24 \mathrm{Mg}(\mathrm{n}, \mathrm{p}) 24 \mathrm{Na}$ & 5 & $14.96 \mathrm{~h}$ & 1368 & 100 \\
\hline In & $\begin{array}{l}115 \operatorname{In}(\mathrm{n} \\
\mathrm{n}) 115 \mathrm{mln}\end{array}$ & 0.34 & $4.486 \mathrm{~h}$ & 335 & 45.83 \\
\hline Co & $59 \mathrm{Co}(\mathrm{n}, \alpha) 56 \mathrm{Mn}$ & 4 & $2.58 \mathrm{~h}$ & 846.7 & 98.90 \\
\hline $\mathrm{Ti}$ & $47 \mathrm{Ti}(\mathrm{n}, \mathrm{p}) 47 \mathrm{Sc}$ & 0.1 & $80.38 \mathrm{~h}$ & 159.37 & 68.30 \\
\hline $\mathrm{Cu}$ & $63 \mathrm{Cu}(\mathrm{n}, \alpha) 60 \mathrm{Co}$ & 2 & 5.27 years & 1173 & 100 \\
\hline $\mathrm{Au}$ & $\begin{array}{l}197 \mathrm{Au}(\mathrm{n}, \\
2 \mathrm{n}) 196 \mathrm{Au}\end{array}$ & 8.25 & 6.18 days & 355 & 87 \\
\hline
\end{tabular}

of high angle $\left(>15^{\circ}\right)$ grain boundaries from 0.317 for UFG to 0.86 in the CG steel. The EBSD pole figures in Fig. 5 display strong $\langle 111\rangle$ surface normal texture while the CG steel exhibits random and homogenous structure with no texture.

\section{Irradiation experiment}

The neutron irradiation experiments on the carbon steel samples were conducted at the NCSU PULSTAR reactor. PULSTAR is a $1 \mathrm{MW}$ open pool research reactor with light water as a moderator, coolant and partial shielding. The reactor is fueled with low enriched $\left(4 \%\right.$ of $\mathrm{U}^{235}$ ) pin-type fuel consisting of uranium dioxide pellets $\left(\mathrm{UO}_{2}\right)$ in Zircaloy cladding. The inherent structure of the PULSTAR core and reactivity considerations did not permit irradiation in the core and a vertical irradiation tube at core boundary was used as irradiation site. The PULSTAR reactor has four ex-core irradiation ports and the nuclear material irradiation was conducted in the west rotation exposure port (WREP) shown in Fig. 8.

The fast neutron flux spectrum at the irradiation location in the reactor was determined using the neutron activation of multiple threshold detectors. Foils of 8 different materials for which the activation reactions cover a range of threshold energies were irradiated for a pre-determined period. Table 1 shows the experimental foils and their threshold energies for different reactions. Induced $\gamma$-ray activity of the irradiated foils was measured using a high purity germanium (HPGe) detector for a period depending on the decay halflives and the foil exposure time. The neutron fluence and its energy distribution are then derived from the measurements of the neutron induced $\gamma$-ray activity in the foils by means of a deconvolution algorithm. STAYSL code [22] was used to solve the dosimetry unfolding problem by the method of least squares to find the flux spectrum. The code uses an iteration method with an initial trial spectrum which is modified until the calculated $\gamma$-ray activities are in agreement with the measured ones within a user preset standard deviation [23]. STAYSL code is available from the Radiation Shielding Information Center (RSIC) at Oak Ridge National Laboratory.

Neutron fluence of the irradiated samples was determined in terms of dpa using the pre-calculated neutron flux spectrum at the irradiation position as an input into SPECTOR code [27]. SPECTER code calculates the number of displacements per atom, in addition to hydrogen and helium gas generation, for an input neutron flux spectrum based on a differential cross section library. The atomic displacement rate was determined to be $1.6 \times 10^{-9} \mathrm{dpa} / \mathrm{s}$ resulting in a dpa of $1.15 \times 10^{-3}$. As run irradiation experiment shows that the maximum ambient temperature of steel samples over the $200 \mathrm{~h}$ of irradiation was about $55^{\circ} \mathrm{C}$ same as the reactor operating temperature [3]. Relatively small specimens needed to be used for irradiation to minimize induced radioactivity as well as due to the limited space available for materials irradiation in the PULSTAR 


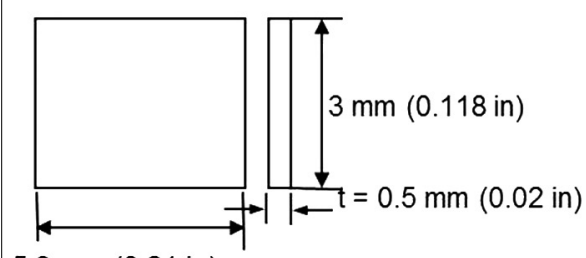

$5.3 \mathrm{~mm}(0.21 \mathrm{in})$

(a)

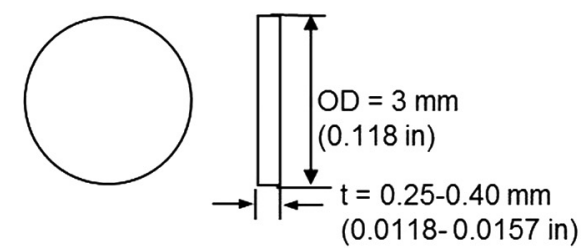

(c)

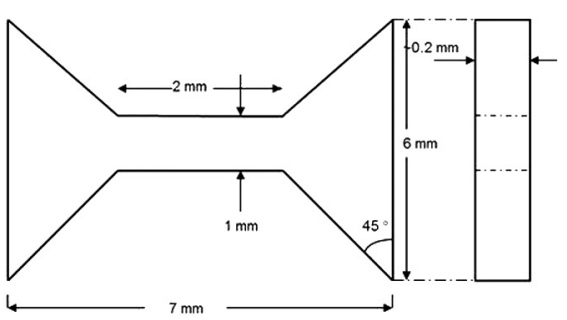

(b)

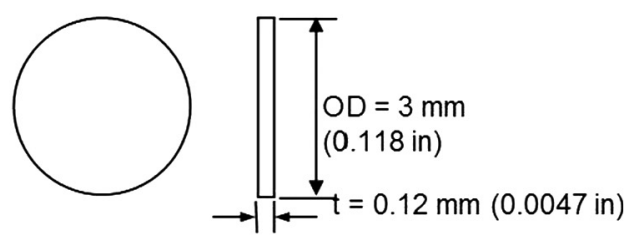

(d)

Fig. 6. Experimental samples designs. (a) Hardness testing block, (b) tensile sample design, (c) TEM sample blank and (d) 3 mm thick discs.

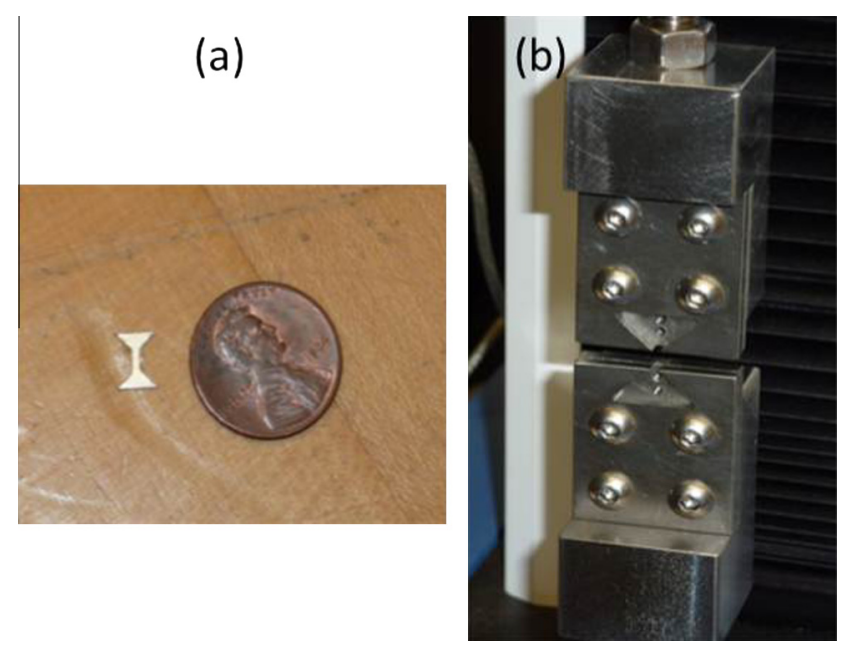

Fig. 7. Photographs of low carbon steel mini tensile sample (a) and tensile test grips (b).

reactor. Small coupons for microhardness and TEM studies along with miniature tensile specimens (Fig. 6) were used to minimize induced radioactivity and the special tensile grips designed for testing miniature tensile samples (Fig. 6b) are included in Fig. 7.

The samples were sealed in quartz tubes and loaded in an aluminum jig that has holes with the same diameter as the quarts tubes (Fig. 8). The jig was inserted in the bottom of a cadmium lined stringer to screen out the low-energy neutrons and thus, reducing the production of long lived radioactive transmutations which will increase the time for the activity to decay before handling the samples safely. The radiation stringer was left in the reactor for about 2.5 months with an effective full power time of $7.2 \times 10^{5} \mathrm{~s}$. After irradiation, all the samples along with the aluminum jig became highly radioactive and thus were left in the reactor pool for more than nine months for the activity to decay so that the samples can be handled without any remote handling facility.

\section{Results and discussion}

Fig. 9 includes optical micrographs of both irradiated and unirradiated CG samples. The average grain size of the CG steel pre and post irradiation was measured to be $4.9 \pm 1.5$ and $6.5 \pm 2.5 \mu \mathrm{m}$ respectively. Grain size measurements for UFG steel were made using both X-ray diffraction (XRD) and transmitted electron microscopy (TEM). XRD patterns for UFG steel before and after irradiation are shown in Fig. 10. The XRD peaks show that there were no phase changes due to irradiation. The full width half maximum (FWHM) of the peaks of similar planes in the XRD patterns of both materials were very close indicating no grain growth after irradiation. In addition, TEM studies were conducted to determine grain size distributions in UFG steel and the bright field TEM images are shown in Fig. 11 for both pre and post irradiation cases. Randomly oriented ultra-fine grain microstructure is observed in both unirradiated and irradiated materials. The TEM images show highly strained areas because of the SPD processing. Contrary to CG steel, no significant grain growth occurred following irradiation. Mean values of $0.35 \pm 0.16$ and $0.36 \pm 0.18 \mu \mathrm{m}$ were found for the grain size respectively for unirradiated material and following neutron radiation exposure.

The small precipitates in the TEM images for the CG steel (Fig. 12) were identified as cementite particles $\left(\mathrm{Fe}_{3} \mathrm{C}\right)$ in grain interior by means of the energy-dispersive X-ray spectrometer (EDS) analysis, and they are believed to arise from annealing at high temperatures. Post irradiation, grain size of CG samples tends to exhibit slight increase albeit very small considering the measurements scatter (grain size distribution); the values are overlapping in terms of the data scatter $(4.9 \pm 1.5$ and $6.5 \pm 2.5 \mu \mathrm{m})$. However, as a consequence of the slight increase in grain size of the CG steel, the grain boundaries are aligned along cementite precipitates (Fig. 13). It was interesting to see increase in the mean grain size of the CG samples albeit small while no significant grain growth was observed in the UFG samples although both samples were at the same location in the reactor during radiation exposure. Thus we believe no significant gamma heating occurred during irradiation. The difference between the two materials is only in the grain size and if the growth was thermally induced then the UFG samples should exhibit far more grain growth contrary to the present observations. We currently do not have an explanation for these observations, and investigations are underway on the same samples irradiated to 1 and 2 dpa levels in the Advanced Test Reactor (ATR) at Idaho National Laboratory (INL) that are expected to yield more information. Increased dislocation density was noted in the CG steel (Fig. 14) while no dislocation networks were noted in UFG steel. 

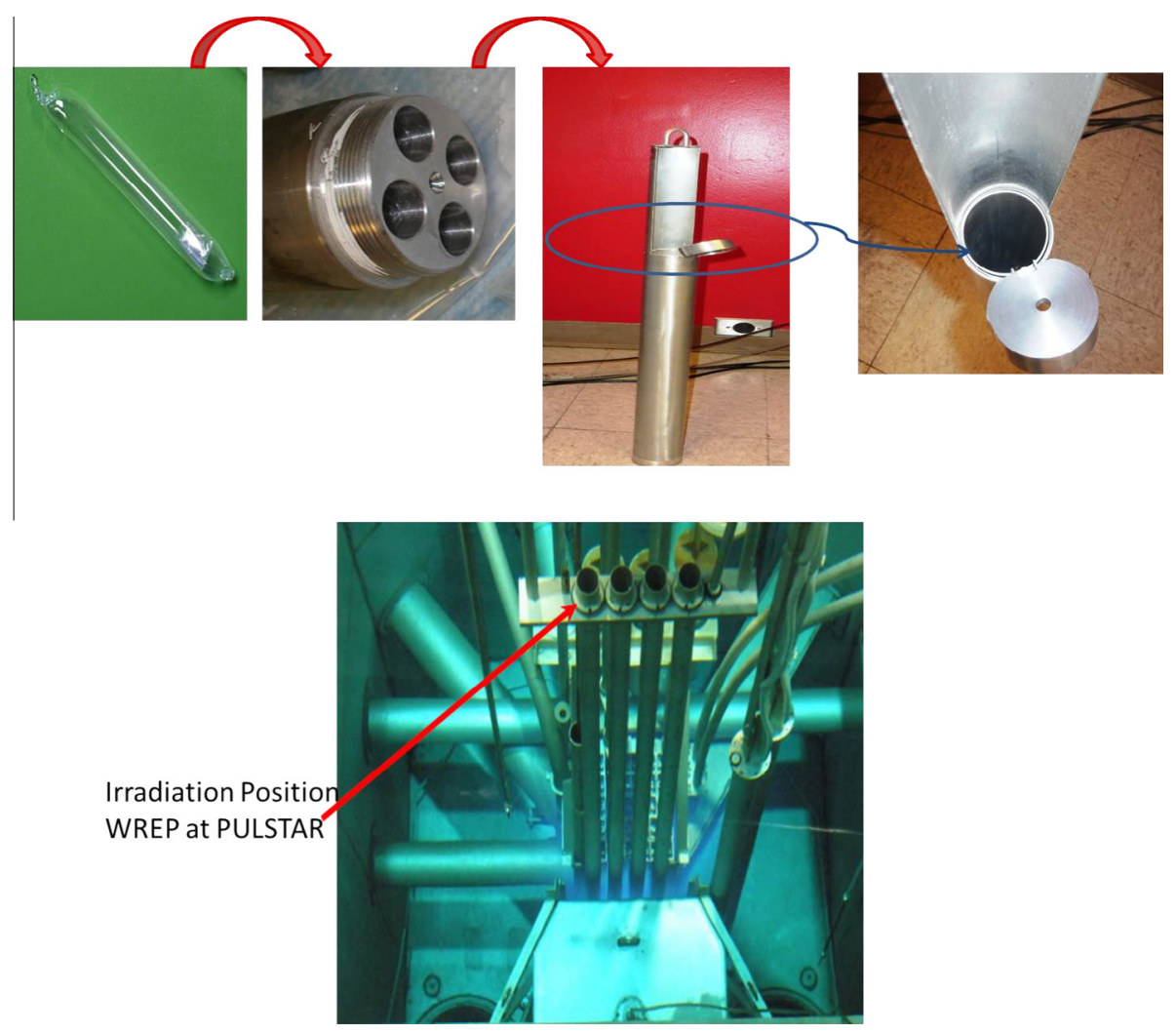

Fig. 8. Irradiation jig and the location in PULSTAR for neutron irradiation.
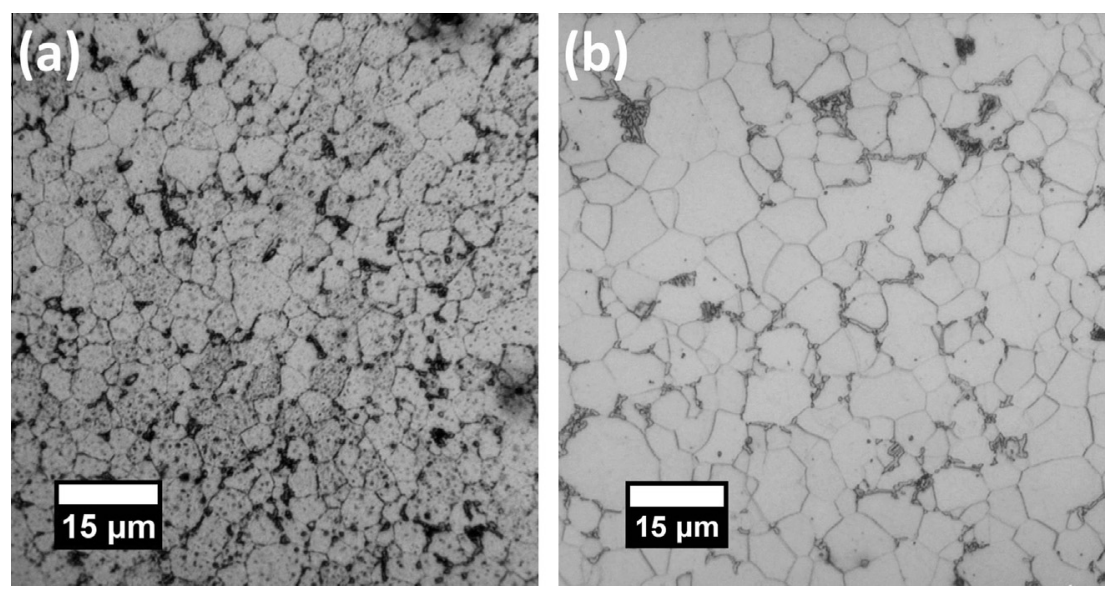

Fig. 9. Microstructure of CG low carbon steel Pre-irradiation (a) and post-irradiation (b).
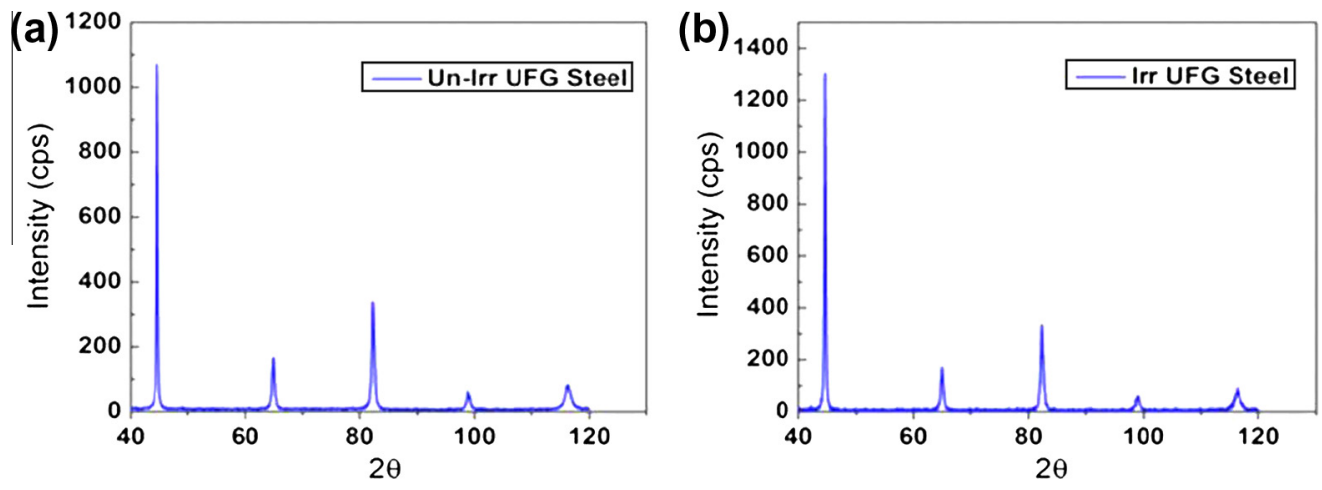

Fig. 10. XRD patterns for UFG steel before (a) and after irradiation (b). 

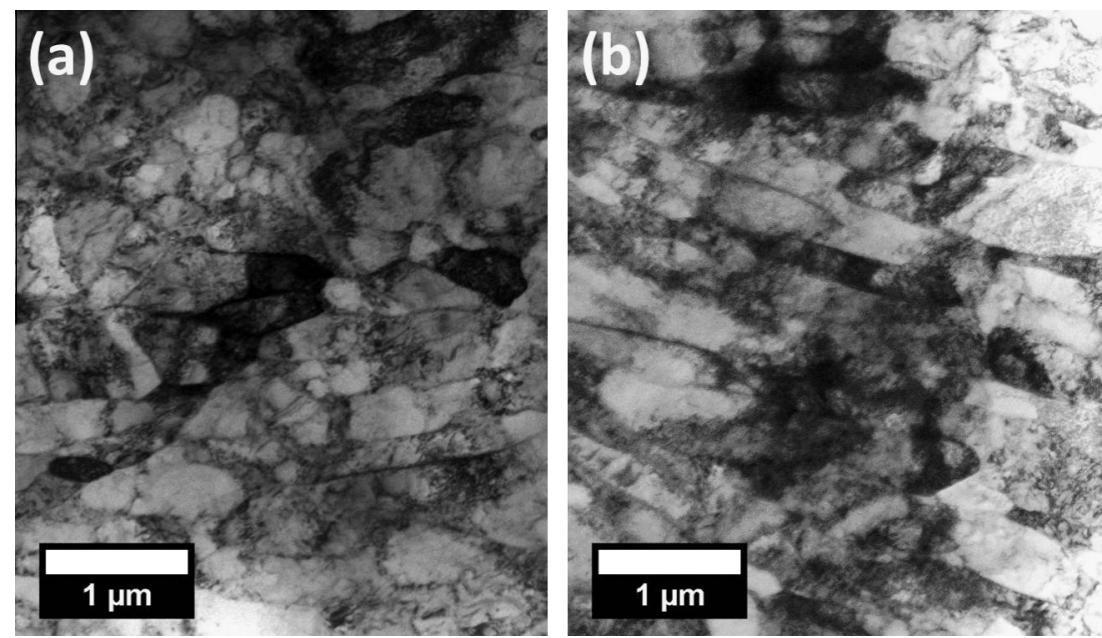

Fig. 11. Bright field TEM for UFG steel before neutron irradiation (a) and after irradiation (b).
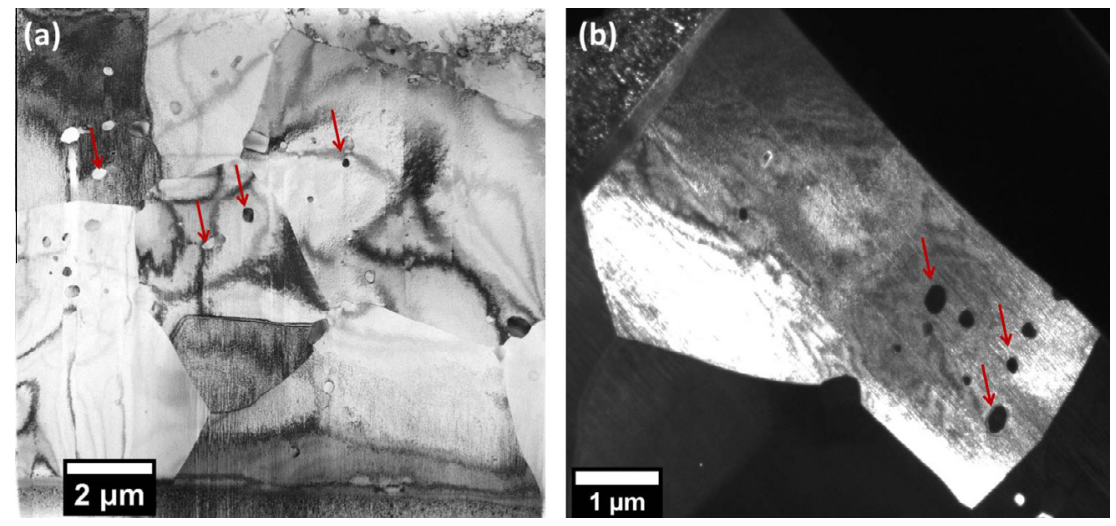

Fig. 12. Bright field (a) and dark field (b) TEM micrographs for un-irradiated CG steel.
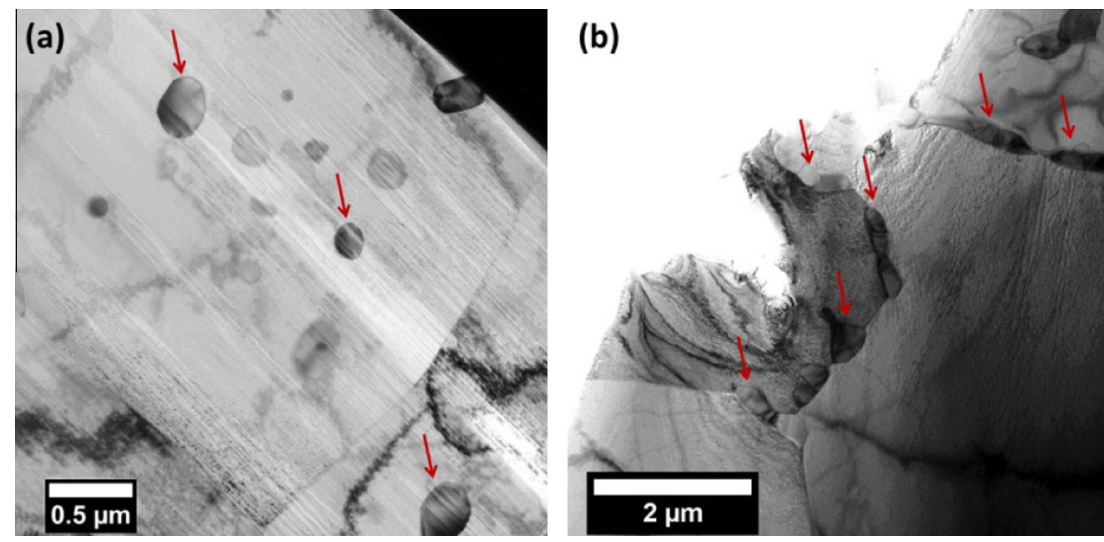

Fig. 13. Cementite particles in CG steel before (a) and after irradiation (b).

Mechanical characteristics were evaluated using Vickers micro hardness as well as tensile tests using mini tensile samples, and the appropriate results are tabulated in Table 2 . Room temperature tensile tests were performed at a strain-rate of $10^{-3} \mathrm{~s}^{-1}$, and three tests were performed for each condition. Fig. 15 includes stress- strain curves for CG and UFG steel before and after neutron irradiation. The loss of strength in the CG compared to the UFG steel before irradiation is due to the grain growth (Hall-Petch relation) and softening of the pearlite due to the spheroidization of pearlitic cementite [28]. After irradiation, the CG steel exhibits increased 

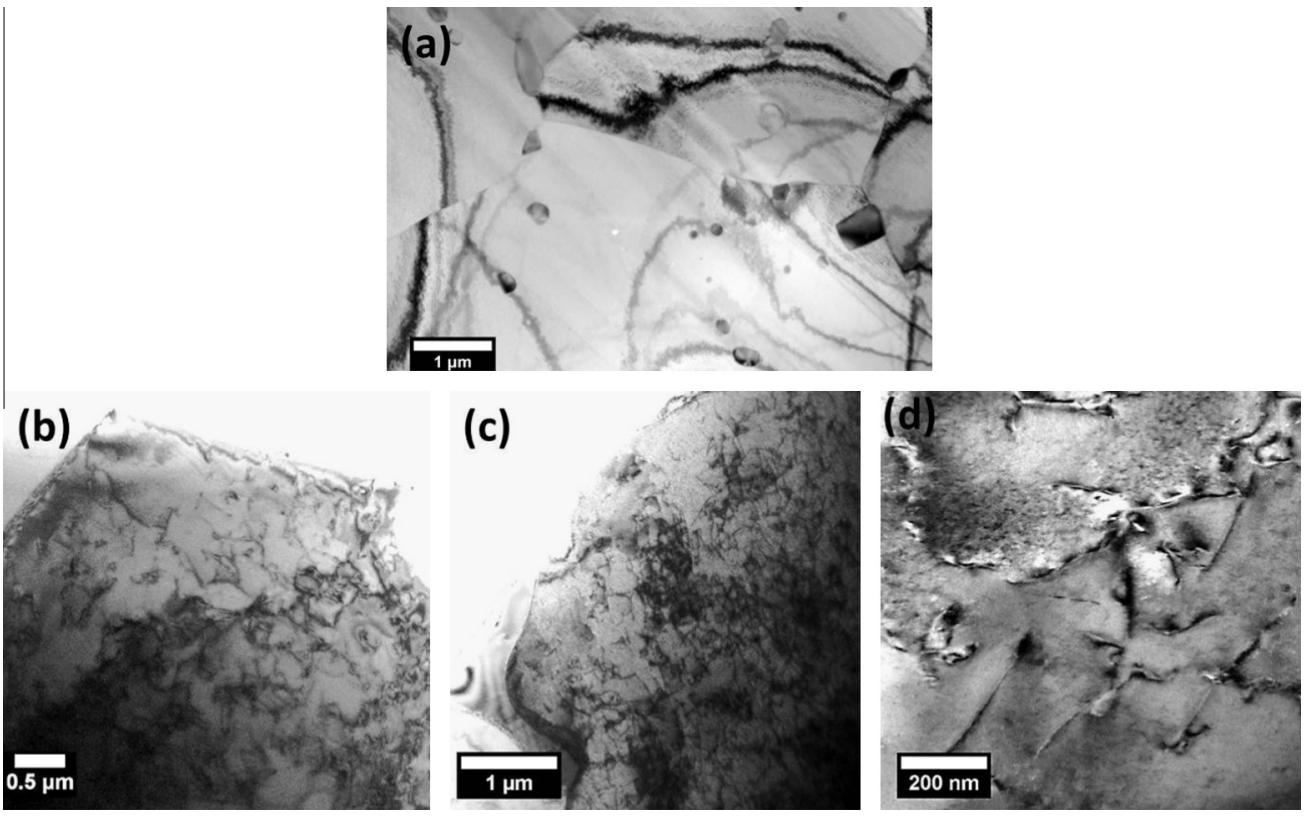

Fig. 14. CG steel before neutron irradiation (a) and after neutron irradiation (b-d) showing high dislocation networks density post irradiation.

Table 2

Mechanical Properties of CG and UFG steel samples before and after neutron radiation exposure.

\begin{tabular}{llllr}
\hline Property & $\begin{array}{l}\text { Un-Irr- } \\
\text { CG }\end{array}$ & $\begin{array}{l}\text { Irr- } \\
\text { CG }\end{array}$ & \multicolumn{1}{l}{$\begin{array}{l}\text { Un-Irr- } \\
\text { UFG }\end{array}$} & \multicolumn{1}{l}{$\begin{array}{l}\text { Irr- } \\
\text { UFG }\end{array}$} \\
\hline Hardness $\pm 3.1(\mathrm{HV})$ & 130.2 & 140.9 & 315.3 & 321.7 \\
Yield stress $(0.2 \%) \pm 8(\mathrm{MPa})$ & 293.9 & 399.8 & 772.9 & 839.8 \\
$\quad$ Ultimate tensile stress \pm 11 & 386.4 & 428.1 & 980.8 & 1042.7 \\
$\quad(\mathrm{MPa})$ & & & & \\
Uniform strain $\left(e_{u}\right) \pm 2(\%)$ & 34.9 & 21.7 & 3.9 & 3.6 \\
Ductility $\pm 2(\%)$ & 63.9 & 45.5 & 18.2 & 16.5 \\
\hline
\end{tabular}

hardness and strength accompanied by decreased ductility as per the commonly observed radiation hardening and embrittlement. However, the UFG steel clearly indicates less significant changes. The increase of hardness in the UFG material was $2 \%$ compared to $8 \%$ increase in the hardness of the CG steel. No yield point phenomena were observed in the UFG steel because impurity atoms (principally carbon) will migrate to the grain boundaries thereby not being available for pinning the dislocation resulting in disappearing of the yield point. The irradiation causes about $36 \%$ increase in the yield stress (YS) of the CG steel while it causes just $9 \%$ increase in the yield strength of UFG steel. The increase in the ultimate tensile stress (UTS) in the UFG steel was $6 \%$ and the reduction in ductility was $9 \%$ as well. In contrast, the increase in the UTS in the CG steel was $11 \%$ and the reduction in the ductility was $29 \%$.

In order to compute the contribution of the irradiation defects on the increase of the yield stress, the linear addition of the strength was used:

$\sigma_{i r r}=\sigma_{0}+\Delta \sigma_{i r r}+\Delta \sigma_{g}$

$\Delta \sigma_{g}=\left(\sigma_{0 i r r}+K_{i r r} \Delta \frac{1}{\sqrt{d_{\text {un-irr }}}}\right)-\left(\sigma_{0 i r r}+K_{i r r} \Delta \frac{1}{\sqrt{d_{i r r}}}\right)$

where $\sigma_{i r r}$ is the post irradiation yield stress, $\sigma_{0}$ is the yield stress before irradiation, $\Delta \sigma_{g}$ is the yield stress contribution attributed to the grain growth following irradiation accounted by Hall-Petch

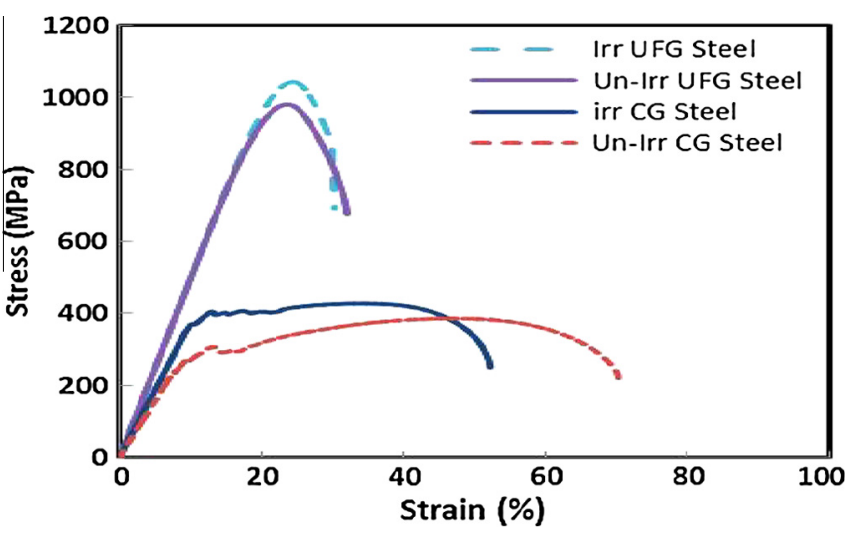

Fig. 15. Stress-strain curves for both un-irradiated and irradiated CG and UFG steels.

equation, $\Delta \sigma_{i r r}$ is the increment in the yield stress due to irradiation induced defects, $d$ is the grain size and $K_{\text {irr }}$ is a constant found to be $345 \mathrm{MPa} \mu \mathrm{m}^{1 / 2}{ }^{1} \Delta \sigma_{\text {irr }}$ for UFG steel was $67 \mathrm{MPa}$ which is equal to $\left(\sigma_{i r r}-\sigma_{0}\right)$ since no grain growth were observed. On other hand $\Delta \sigma_{i r r}$ for the CG steel is found to be $131 \mathrm{MPa}$; this shows that the large fraction of grain boundaries in UFG steel acts as sinks for irradiation induced defects resulting in less influence of the irradiation defects in increasing the strength of the UFG materials.

The fracture surfaces of the tensile specimens were investigated by SEM for both UFG and CG materials before and after irradiation (Fig. 16). While no significant differences were observed in the UFG fracture surface before and after irradiation, the CG steel shows decrease in the diameter of the dimpled rupture depressions indicating less time needed for fracture and thus less ductility.

\footnotetext{
${ }^{1} \mathrm{~K}$ value derived from the strength and grain size data of irradiated CG and UFG steels.
} 

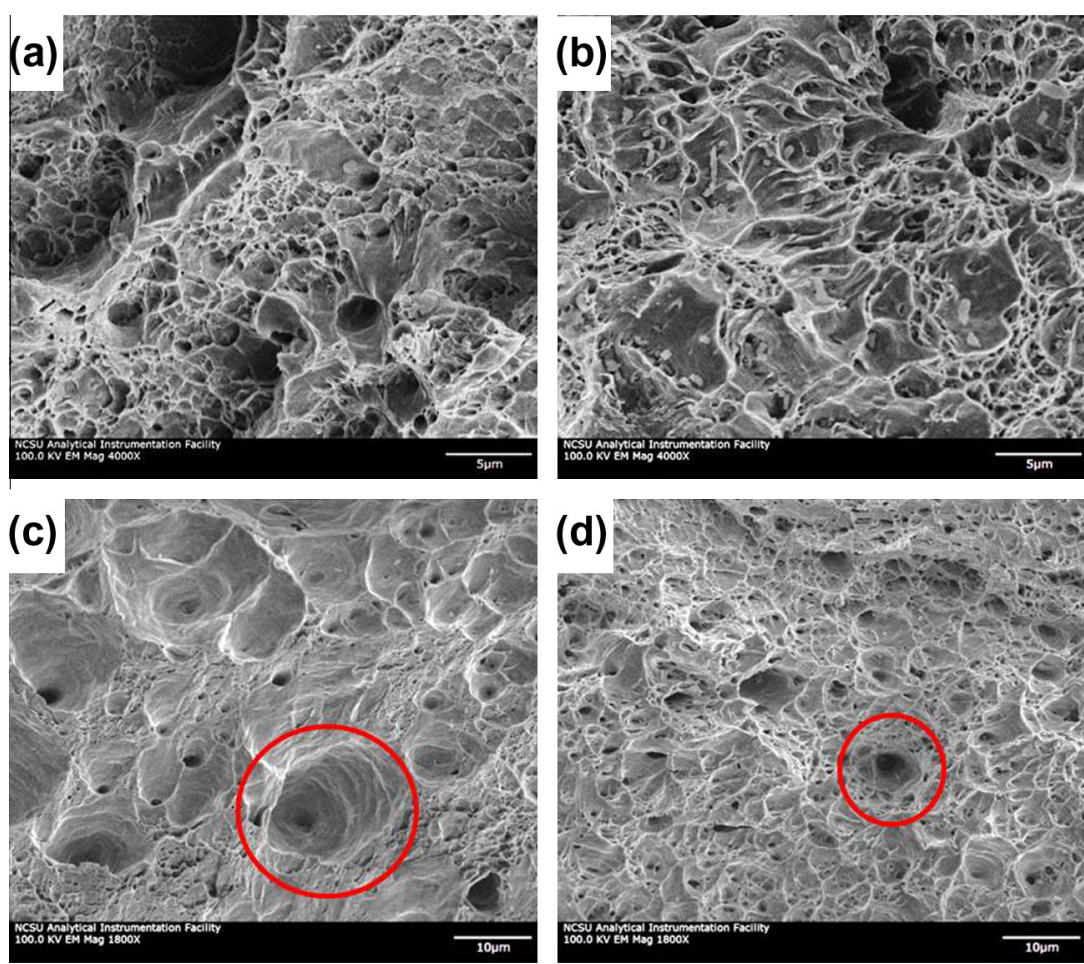

Fig. 16. Fractography SEM images for (a) UFG steel before irradiation, (b) UFG steel post irradiation, (c) CG steel before irradiation and (d) CG steel post irradiation.

\section{Conclusions}

UFG steel processed via ECAP tends to exhibit better low dpa irradiation tolerance than CG steel, indicating that UFG steel could be a promising candidate of the new structural material for reactor applications. Reduction of the irradiation effect on both the ductility and strength of the ECAP steel could be explained by larger grain boundary volume fraction in UFG state. Current studies were performed at relatively low dpa and investigations are underway to characterize neutron radiation effects in these steels following higher irradiation doses $(1-2 \mathrm{dpa})$ in the ATR test reactor at Idaho National Laboratories.

\section{Acknowledgements}

This work is supported by the ATR NSUF and we acknowledge the CAES/INL personnel for assistance in many experimental aspects.

\section{References}

1] K.L. Murty, I. Charit, J. Nucl. Mater. 383 (2008) 189.

[2] K.L. Murty, J. Nucl. Energy Sci. Power Gen. Technol. (2012) 1.

[3] W. Mohamed, Influence of Fast Neutron Irradiation on Mechanical Properties and Microstructure of Nanocrystalline Copper, PhD Dissertation, North Carolina State University, 2012.
[4] B.N. Singh, Philos. Mag. 29 (1) (1974) 25

[5] R.A. Andrievski, Rev. Adv. Mater. Sci. 29 (2011) 54

[6] M. Rose, Nucl. Instrum. Methods Phys. Res. 128 (1997) 119.

[7] N. Nita, R. Schaeublin, M. Victoria, R.Z. Valiev, Philos. Mag. 85 (2005) 723.

[8] T. Mutschele, R. Kirchheim, Scr. Metall. 21 (1987) 135

[9] R.Z. Valiev, Mater. Sci. Forum 584-586 (2008) 22

[10] C.C. Koch, Nanostructured Materials: Processing, Properties and Potentia Applications, second, Norwich, 2007

11] C. Cheung, G. Palumbo, U. Erb, Scr. Metall. Mater. 31 (1994) 735

[12] H. Gleiter, Prog. Mater. Sci. 33 (1989) 223.

13] R.S. Averback, H.J. Höfler, R. Tao, Mater. Sci. Eng., A 166 (1993) 169.

[14] R. Valiev, R. Islamgaliev, I. Alexandrov, Prog. Mater. Sci. 45 (2000) 103.

[15] A. Zhilyaev, T. Langdon, Prog. Mater. Sci. 53 (2008) 893.

[16] V.V. Stolyarov, Y.T. Zhu, I.V. Alexandrov, T.C. Lowe, R.Z. Valiev, Mater. Sci. Eng. A 299 (2001) 59.

[17] R. Valiev, T.G. Langdon, Rev. Adv. Mater. 13 (2006) 15

[18] K. Nakashima, Z. Horita, M. Nemoto, T.G. Langdon, Mater. Sci. Eng. A 281 (2000) 82.

[19] M. Furukawa, Y. Iwahashi, Z. Horita, M. Nemoto, T.G. Langdon, Mater. Sci. Eng. A 257 (1998) 328

[20] V.M. Segal, Mater. Sci. Eng. A 197 (1995) 157.

[21] Y. Iwahashi, J. Wang, Z. Horita, M. Nemoto, T.G. Langdon, Scripta Mater. 35 (1996) 143.

[22] F.G. Perey, Least-Squares Dosimetry Unfolding: The Program STAY'SL, 1977.

[23] C.C. Negoita, Measurement of Neutron Flux Spectra in a Tungsten Benchmark by Neutron Foil Activation Method, Dresden University of Technology, 2004

[24] Chart of Nuclides (official Web Site of the Iaea), 2012.

[25] Lawrence Berkeley National Laboratory, 2012.

[26] WebElements Periodic Table of the Elements, 2012.

[27] L.R. Greenwood, R.K. Smither, SPECTER: Neutron Damage Calculations for Materials Irradiations, 1985.

[28] K.T. Park, Y.S. Kim, D.H. Shin, Metall. Mater. Trans. A 32 (2001) 2373. 